УДК 391.316

К вопросу применения материалов

на основе дисперсных гидросиликатов кальция при устройстве защитных покрытий местных автомобильных дорог

Докт. хим. наук, проф. В. Н. Яглов ${ }^{1)}$, доктора техн. наук, профессора Я. Н. Ковалев ${ }^{1)}$, В. Н. Романюк ${ }^{1)}$, А. В. Таболич ${ }^{2)}$, Е. Н. Иванов ${ }^{2)}$

${ }^{1)}$ Белорусский национальный технический университет (Минск, Республика Беларусь),

${ }^{2)}$ НТЦ ООО «НПО Центр» (Минск, Республика Беларусь)

(c) Белорусский национальный технический университет, 2016

Belarusian National Technical University, 2016

Реферат. Строительство автомобильных дорог - одна из наиболее материалоемких сфер промышленного производства. В этой связи для данной отрасли актуальной задачей является максимальное снижение материалоемкости строительства путем применения эффективных местных материалов, снижения энергоемкости технологических процессов за счет использования новых материалов. Развитая сеть местных автомобильных дорог требует постоянного ухода и текущего ремонта. Поэтому целесообразно рассмотреть вопрос использования защитных покрытий таких дорог на основе материалов контактно-конденсационного твердения, которые могут быть получены на базе местного сырья. Одним из представителей таких материалов являются дисперсные гидросиликаты кальция, которые находят широкое практическое применение в качестве основных компонентов при производстве строительных материалов, стекла, ситаллов, керамических изделий. Относительно дешевый высокодисперсный кристаллический материал промежуточный продукт гидрохимического синтеза волластонита - ксонотлит $\mathrm{Ca}_{6}\left(\mathrm{Si}_{6} \mathrm{O}_{17}\right)(\mathrm{OH})_{2}$. Разнообразие кальций- и кремнийсодержащего сырья, пригодного для получения различного вида гидросиликатов кальция, повышения требований к физико-химическим свойствам, обусловливает актуальность проблемы поиска и изучения оптимальных путей синтеза гидросиликатов кальция из техногенного и природного сырья. Теоретической основой предлагаемой технологии получения материала для покрытий дорог низких категорий является способность силикатных дисперсных веществ, переведенных в нестабильное состояние, образовывать камнеподобное водостойкое тело в момент приложения механической нагрузки. Дисперсные гидросиликаты кальция - наиболее характерные представители таких вяжущих контактно-конденсационного твердения. Следует отметить, что технология получения этих вяжущих не связана с высокотемпературными процессами, а синтез гидросиликатов кальция реализуется при тепловлажностной обработке доступного дешевого сырья на серийном оборудовании, что определяет их практическую значимость.

Ключевые слова: дисперсный гидросиликат кальция, автомобильная дорога, защитное покрытие

Для цитирования: К вопросу применения материалов на основе дисперсных гидросиликатов кальция при устройстве защитных покрытий местных автомобильных дорог / В. Н. Яглов [и др.] // Наука и техника. 2016. Т. 15, № 2. С. 122-125

\title{
On Application of Materials Based on Disperse Hydrated Calcium Silicate for Protective Layer of Local Automobile Roads
}

\author{
V. N. Yaglov'), Ya. N. Kovalev'), V. N. Romaniuk ${ }^{1)}$, A. V. Tabolich ${ }^{2)}$, Ye. N. Ivanov ${ }^{2)}$ \\ ${ }^{1)}$ Belarusian National Technical University (Minsk, Republic of Belarus), \\ ${ }^{2)}$ OJSC "NPO Center" (Minsk, Republic of Belarus)
}

\begin{abstract}
Road construction is one of the most material-intensive spheres of industrial production. In this context, a relevant problem for the given branch is a maximum reduction of material consumption in construction through application of efficient local materials, decrease of power consumption in technological processes by using new materials. The developed network of local automobile roads requires their constant servicing and maintenance. So it is expedient to consider usage of protective coatings for such roads on the basis of materials having contact-condensation hardening and which can be obtained with the help of local raw materials. One of the representatives of such materials is disperse hydrated calcium silicate which has
\end{abstract}

Адрес для переписки

Романюк Владимир Никанорович

Белорусский национальный технический университет

просп. Независимости, 65/2,

220013, г. Минск, Республика Беларусь

Тел.: +375 17 293-92-16

pte@bntu.by

\author{
Address for correspondence \\ Romaniuk Vladimir N. \\ Belarusian National Technical University \\ 65/2 Nezavisimosty Ave., \\ 220013, Minsk, Republic of Belarus \\ Tel.: +375 17 293-92-16 \\ pte@bntu.by
}


found wide practical application as main components in the production of building materials, glass, glass ceramics and ceramic products.For example, relatively cheap highly dispersed crystalline material is intermediate product of hydro-chemical synthesis of wollastonite - xonotlite $\mathrm{Ca}_{6}\left(\mathrm{Si}_{6} \mathrm{O}_{17}\right)(\mathrm{OH})_{2}$. A variety of calcium and silicon-containing raw material which is suitable to obtain various types of hydrated calcium silicate, to raise requirements for physical and chemical properties, dictates a need to search and study optimal ways for synthesis of hydrated calcium silicate from man-made and natural materials. The theoretical basis of the proposed technology to produce material required for secondary road pavement surfacing is the ability of silicate dispersed materials transferred in an unstable state to form a rock-like waterproof body at the moment of mechanical load application. Disperse hydrated calcium silicate are the most typical representatives of such binders with contact-condensation hardening. It is important to note that the technology for obtaining these binders is not related to hightemperature processes, and a synthesis of hydrated calcium silicates is realized while using steam curing of the available cheap raw material on the standard equipment. So such technology determines practical significance of the binders.

Keywords: disperse hydrated calcium silicate, automobile road, protective coating

For citation: Yaglov V. N., Kovalev Ya. N., Romaniuk V. N., Tabolich A. V., Ivanov Ye. N. (2016) On Application of Materials Based on Disperse Hydrated Calcium Silicate for Protective Layer of Local Automobile Roads. Science \& Technique. 15 (2), 122-125 (in Russian)

Bсе методы получения дисперсных гидросиликатов кальция (ГСК) нестабильного состояния можно разделить на две группы - «снизу вверх» и «сверху - вниз».

Метод «снизу - вверх» предусматривает получение ГСК из раствора исходных солей методом осаждения. Анализ факторов, влияющих на процесс формирования твердой фазы, позволил экспериментально определить оптимальные условия осаждения ГСК в виде нанодисперсных порошков. В частности, установлено, что температура, при которой протекает процесс осаждения, - важный фактор, влияющий на дисперсность получаемых порошков ГСК. Снижение температуры синтеза способствует уменьшению агломератов, повышению удельной поверхности осадка, так как происходит уменьшение скорости растворения мелких частиц осаждаемых ГСК (табл. 1) [1].

Таблиия 1

Характеристики порошков гидросиликатов кальция, полученных при различных температурах осаждения [1]

Characteristics of hydrated calcium silicate powder obtained at various precipitation temperature [1]

\begin{tabular}{|c|c|c|c|}
\hline $\begin{array}{c}\text { Тип исходной } \\
\text { системы }\end{array}$ & $\begin{array}{l}\text { Темпера- } \\
\text { тура оса- } \\
\text { ждения, }{ }^{\circ} \mathrm{C}\end{array}$ & $\begin{array}{c}\text { Размер } \\
\text { агломе- } \\
\text { ратов, мкм }\end{array}$ & \begin{tabular}{|c|} 
Удельная \\
поверхность \\
образцов, \\
м $^{2} / \Gamma$
\end{tabular} \\
\hline $\begin{array}{l}\mathrm{CaCl}_{2(\mathrm{p})}- \\
-\mathrm{Na}_{2} \mathrm{SiO}_{3(\mathrm{p})}-\mathrm{H}_{2} \mathrm{O}\end{array}$ & $\begin{array}{c}35 \\
20 \\
6 \\
1\end{array}$ & $\begin{array}{c}12-30 \\
5-14 \\
0,5-1,0 \\
0,5-1,0\end{array}$ & $\begin{array}{l}10-12 \\
40-44 \\
85-92 \\
90-92\end{array}$ \\
\hline $\begin{array}{l}\mathrm{Ca}\left(\mathrm{NO}_{3}\right)_{2(\mathrm{p})}- \\
-\mathrm{Na}_{2} \mathrm{SiO}_{3(\mathrm{p})}-\mathrm{H}_{2} \mathrm{O}\end{array}$ & $\begin{array}{c}35 \\
20 \\
6 \\
1\end{array}$ & $\begin{array}{c}15-30 \\
5-10 \\
<0,5 \\
<0,5\end{array}$ & $\begin{array}{c}7-13 \\
30-35 \\
78-84 \\
80-82\end{array}$ \\
\hline $\begin{array}{l}\mathrm{Ca}\left(\mathrm{CH}_{3} \mathrm{COOH}\right)_{2(\mathrm{p})}- \\
-\mathrm{Na}_{2} \mathrm{SiO}_{3(\mathrm{p})}-\mathrm{H}_{2} \mathrm{O}\end{array}$ & $\begin{array}{c}35 \\
20 \\
6 \\
1\end{array}$ & $\begin{array}{l}1-20 \\
1-15 \\
<0,5 \\
<0,5\end{array}$ & $\begin{array}{c}8-10 \\
60-64 \\
85-92 \\
85-92\end{array}$ \\
\hline
\end{tabular}

Наука
По данным рентгенофазового анализа, полученные ГСК рентгеноаморфны. Термогравиметрический анализ показал, что синтезированные ГСК содержат около 30 \% воды, выделяющейся при нагревании в интервале $20-700{ }^{\circ} \mathrm{C}$.

Учитывая экономическую сторону вопроса синтеза ГСК, были изучены также способы их получения в системах:

- фосфогипс - растворимое стекло - вода;

- фосфогипс - негашеная известь - вода;

- негашеная известь - кремнегель - вода [2-6].

Кинетику формирования силикатов в указанных системах контролировали по выходу сульфат-ионов в раствор

$$
\begin{gathered}
n \mathrm{CaSO}_{4} \cdot 2 \mathrm{H}_{2} \mathrm{O}+m \mathrm{Na}_{2} \mathrm{SiO}_{3}+ \\
+(k+2 n) \mathrm{H}_{2} \mathrm{O} \underset{\mathrm{CaO}}{\rightarrow} n \rightarrow m \mathrm{SiO}_{2} \cdot k \mathrm{H}_{2} \mathrm{O}+ \\
n \mathrm{Na}_{2} \mathrm{SO}_{4} .
\end{gathered}
$$

Процесс синтеза ГСК протекал при силикатном модуле $\mathrm{Na}_{2} \mathrm{SiO}_{3}=1$ и при $m=n$. Выход готового продукта (ГСК) при семичасовом синтезе составил 62,6 \%. Дальнейшее увеличение времени концентрирования конечного продукта нецелесообразно, поскольку его выход в ходе процесса возрастает незначительно. Так, при 48-часовом синтезе он достигал $67 \%$.

На основании данных рентгенофазового анализа в осадках, полученных при взаимодействии фосфогипса и жидкого стекла и высушенных при комнатной температуре, присутствовали ГСК в виде аморфной фазы, а кристаллическая фаза была представлена $\mathrm{CaSO}_{4} \cdot 2 \mathrm{H}_{2} \mathrm{O}[2-6]$.

Процесс синтеза ГСК из аморфного кремнезема (кремнегель) - негашеной извести в присутствии щелочного агента $(\mathrm{NaOH})$ при $\mathrm{pH}=13$ включает следующие стадии:

1) $\mathrm{SiO}_{2} \cdot n \mathrm{H}_{2} \mathrm{O}+2 \mathrm{NaOH}=\mathrm{Na}_{2} \mathrm{SiO}_{3}+$ $+(n+1) \mathrm{H}_{2} \mathrm{O}$

2) $\mathrm{CaO}+\mathrm{H}_{2} \mathrm{O}=\mathrm{Ca}(\mathrm{OH})_{2}$; 
3) $n \mathrm{Ca}(\mathrm{OH})_{2}+m \mathrm{Na}_{2} \mathrm{SiO}_{3}+k \mathrm{H}_{2} \mathrm{O}=n \mathrm{CaO} \times$ $\times m \mathrm{SiO}_{2} \cdot k \mathrm{H}_{2} \mathrm{O}+2 m \mathrm{NaOH}$.

Размер зерен синтезированного ГСК составлял 1-20 мкм. Как вариант данный вид синтеза ГСК во всех вышеуказанных системах может быть использован для получения волластонита путем термообработки ГСК.

Метод «сверху - вниз» предусматривает синтез дисперсных ГСК в системе молотый кварцевый песок - негашеная известь - вода. Авторы использовали данный метод синтеза. Для этого песок подвергали помолу на измельчительном комплексе КИ-04 с помощью центробежно-ударного механизма измельчения. В сепараторе были выделены три фракции молотого песка - частицы менее:

- 20 мкм;

- 40 мкм;

- 120 мкм.

Определили удельные поверхности этих фракций песка. Они составили соответственно 1,$0 ; 0,73$ и $0,23 \mathrm{~m}^{2} /$ г. Поглотительная способность $\mathrm{CaO}$ отдельных фракций соответственно 200; 180; 80 мг СаO/Г молотого песка. Для сравнения, поглотительная способность трепела 390 мг $\mathrm{CaO} / \Gamma$ трепела. Вяжущее (ГСК) из смеси состава: песок (фракция $<20$ мкм) - $40 \%$ мас., известь $(72 \% \mathrm{CaO})-20 \%$ мас. и трепел (фракция $<60$ мкм) - $40 \%$ мас. получали путем кипячения водной суспензии при $\mathrm{B} / \mathrm{T}=4$ в течение 2 ч. В конце кипячения в полученное из ГСК вяжущее добавляли грубомолотый песок (фракция $<120$ мкм) при соотношении Вяж:П = $=2: 1$. Влажность полученной смеси составляла 16-18 \%. Из этой смеси прессовали образцыцилиндры диаметром 50 мм и высотой 50 мм. Прочность образцов сразу после прессования при давлении прессования 20 МПа составила 6 МПа, при давлении прессования 40 МПа - 11 МПа. Через 28 сут. воздушного хранения предел прочности на сжатие тех же образцов увеличился до 9 и 15 МПа соответственно.

Следует отметить, что синтез ГСК по методу «сверху - вниз» близок к уже используемым в промышленности строительных материалов методам механико-химической активации сырьевых материалов при производстве силикатного кирпича. Мерой механоактивации можно считать количество накопленной поверхностной энергии, запасенной в виде низкоэнергетичных дефектов, существенно снижающих энергию активации реакции химического взаимодействия извести и песка и повышающих кинетические константы процессов. Наличие этих дефектов обусловливает более высокую степень разупорядоченности структуры. Чем их больше, тем ближе вещество к химически активному аморфному состоянию [4]. В технологии силикатных материалов во многих процессах синтеза ГСК основной лимитирующий фактор - низкая химическая активность кварцевого компонента. В $[5,6]$ наглядно представлено позитивное влияние механоактивации на процессы взаимодействия кремнеземистого компонента с получением различных продуктов. Замечено, что в большей степени механоактивации подвергаются твердые и хрупкие материалы с большой долей ковалентных связей, в то время как пластические компоненты с идеальной спаянностью почти не поддаются активации такого рода. Очевидно, при механических нагрузках происходит скольжение структурных элементов твердых материалов относительно друг друга. С этой точки зрения кварцевые пески и сырьевые смеси на их основе являются материалами, восприимчивыми к механической активации $[7,8]$.

Основные результаты исследований механоактивационной диспергации кварцевого минерального сырья - установление аморфизации поверхности кварцевых частиц и уменьшение размеров кристаллитов. В частности, для неактивированного кварца размер кристаллитов оценивался $>100$ нм. Частицы механоактивированного кварца состоят из двух областей - центральной кристаллической области с размером кристаллитов $\sim 90$ нм и поверхностного аморфизованного слоя толщиной около 20 нм и размерами кристаллитов 1-10 нм [9-11].

Необходимо отметить, что если минералы группы кремнезема представляют собой высокотермические и высокобарические полиморфные модификации, при механоактивации кварца возможна реализация двух релаксационных процессов - агрегирование и возникновение в матрице материала высокотемпературных полиморфных модификаций. При этом логично предполагать, что различия в термической истории кварцевого сырья разных минералого-генетических типов могут существенно повлиять на финальное состояние этих материалов после механоактивационной диспергации, в частности на их фазовую и размерную нанои микрогетерогенность. 


\section{ВЫВОДЫ}

1. При получении нестабильных дисперсных гидросиликатов кальция можно использовать два метода:

- «снизу - вверх» - осаждение гидросиликатов кальция из раствора при взаимодействии водорастворимых солей;

- «сверху - вниз» - путем использования теплового, химического и механического методов активации сырьевых компонентов для повышения дефектности их структуры.

2. Полученные смеси можно транспортировать на строящуюся дорогу, равномерно распределять смесь по ней и прикатывать вначале легкими, а затем тяжелыми катками. При этом образуется камневидное водостойкое покрытие [12].

\section{ЛИТЕРАТУРА}

1. Акатьева, Л. В. Развитие химико-технологических основ процессов переработки сырья для получения силикатов кальция и композиционных материалов / Л. В. Акатьева. М., 2014. 74 с.

2. Формирование моносиликатов кальция в модельной системе $\mathrm{CaSO}_{4} \cdot 2 \mathrm{H}_{2} \mathrm{O}-\mathrm{Na}_{2} \mathrm{SiO}_{3} /$ П. С. Гордиенко [и др.] // Перспективные материалы. 2008. № 6. С. 136-139.

3. Ярусова, С. Б. Синтез силикатов кальция в многокомпонентных системах и их физико-химические свойства / С. Б. Ярусова. Владивосток, 2010. 28 с.

4. Исследование кинетических особенностей формирования моносиликата кальция в модельной системе $\mathrm{CaSO}_{4} \cdot 2 \mathrm{H}_{2} \mathrm{O}-\mathrm{Na}_{2} \mathrm{O}-\mathrm{SiO}_{2} /$ П. С. Гордиенко [и др.] // Журнал прикладной химии. 2009. Т. 82, вып. 9. C. $1409-1413$.

5. Моносиликаты кальция как компоненты композиционных материалов / П. С. Гордиенко [и др.] // Химическая технология. 2009. Т. 10, № 3. С. 143-149.

6. Получение ксонотлита и перспективы его применения / В. Д. Гладун [и др.] // Химическая технология. 2000. Т. 1, № 11. С. $2-9$.

7. Глуховский, В. Д. Физико-химические основы конденсации минеральных дисперсий / В. Д. Глуховский, Р. Ф. Рунова, П. В. Кривенко. Киев: Знание, 1983. 16 с.

8. Глуховский, В. Д. Сравнительная оценка контактноконденсационных свойств дисперсных гидросиликатов кальция и щелочных гидроалюмосиликатов, гидратация и твердение вяжущих / В. Д. Глуховский, Р. Ф. Рунова, В. И. Чернявский // Гидратация и твердение вяжущих: тезисы докл. IV Всесоюзн. совещания. Львов, 1986. С. 167-170.

9. Тихомирова, И. Н. Механоактивация известково-кварцевых вяжущих / И. Н. Тихомирова, А. В. Макаров // Строительные материалы. 2012. № 9. С. 5-7.

10. Структурные преобразования кварцевого сырья при механоактивации / И. В. Жерновский [и др.] // Строительные материалы. 2012. № 10. С. 56-58.

11. Артамонова, О. В. Концепции и основания технологий наномодифицирования структур строительных композитов / О. В. Артамонова, Б. М. Чернышев // Строительные материалы. 2013. № 9. С. 82-90.
12. Чернявский, В. И. Строительные материалы из дисперсных гидросиликатов кальция / В. И. Чернявский. Киев, 1985. С. 22.

Поступила 25.05.2015

Подписана в печать 31.07.2015

Опубликована онлайн 30.03.2016

\section{REFERENCES}

1. Akatieva L. V. (2014) Development of Chemical and Technological Principles for Raw Material Processing in Order to Obtain Calcium Silicate and Composite Materials. Moscow. 74 (in Russian).

2. Gordienko P. S., Suponina A. P., Yarusova S. B., Bulanova S. B., Krysenko G. F., Kolzunov V. A. (2008) Formation of Calcium Mono-Silicates in the Model System $\mathrm{CaSO}_{4} \cdot 2 \mathrm{H}_{2} \mathrm{O}-\mathrm{Na}_{2} \mathrm{SiO}_{3}$. Perspektivnye Materialy [Prospective Materials], (6), 136-139 (in Russian).

3. Yarusova S. B. (2010) Synthesis of Calcium Silicates in Multi-Component Systems and their Physical and Chemical Properties. Vladivostok. 28 (in Russian).

4. Gordienko P. S., Suponina A. P., Yarusova S. B., Bulanova S. B., Krysenko G. F., Kolzunov V. A. (2009) Study of the Kinetic Aspects of Formation of Calcium Mono-Silicate in the Model System $\mathrm{CaSO}_{4} \cdot 2 \mathrm{H}_{2} \mathrm{O}-\mathrm{Na}_{2} \mathrm{O}-\mathrm{SiO}_{2}$. Russian Journal of Applied Chemistry, 82 (9), 1505-1509. DOI: $10.1134 / \mathrm{S} 1070427209090018$.

5. Gopdienko P. S., Yarusova S. B., Bulanova S. B., Kolzunov V. A., Suponina A. P., Galkin K. N. (2009). Calcium Mono-Silicates as Components of Composite Materials. Khimicheskaya Tekhnologia [Chemical Technology], 10 (3), 143-149 (in Russian).

6. Gladun V. D., Akateva L. V., Andreeva N. N., Kholkin A. I. (2000) Obtaining of Xonotlite and its Application. Khimicheskaya Tekhnologia [Chemical Technology], 1 (11), 2-9 (in Russian)

7. Glukhovsky V. D., Runova R. F., Krivenko P. V. (1983) Physical and Chemical Principles for Condensation of Mineral Dispersions. Kiev, Znanie. 16 (in Russian).

8. Glukhovsky V. D., Runova R. F., Chernyavsky V. I. (1986) Comparative Estimation of Contact and Condensation Properties of Dispersive Calcium Hydro-Silicates and Alkaline Hydroalumosilicates, Hydration and Solidification of Binders. Hydration and Hardening Binders. Report Abstracts of IV All-Union Meeting. Lvov, 167-170 (in Russian).

9. Tikhomirova I. N., Makarov A. V. (2012) Mechanical Activation of Lime-Quartz Binders. Stroitelnye Materialy [Construction Materials], (9), 5-7 (in Russian).

10. Zhernovskii I. V., Strokova V. V., Bondarenko A. I., Kozhukhova N. I., Sobolev K. G. (2012) Structural Transformations of Quartz Raw Material Durin Mechanical Activation. Stroitelnye Materialy [Construction Materials], (10), 56-58 (in Russian).

11. Artamonova O. V., Chernyshev B. M. (2013) Conception and Principles of Technology for Nano-Modification of Construction Composite Structures. Stroitelnye Materialy [Construction Materials], (9), 82-90 (in Russian).

12. Chernyavsky V. I. (1985) Construction Materials from Dispersive Calcium Hydro-Silicates. Kiev. 22 (in Russian).

Received: 25.05 .2015

Accepted: 31.07 .2015

Published online: 30.03 .2016 